\title{
Tunnel memories for autobiographical events: Central details are remembered more frequently from shocking than from happy experiences
}

\author{
DORTHE BERNTSEN \\ University of Aarhus, Risskov, Denmark
}

\begin{abstract}
In three experiments, undergraduates recorded as many details as possible for autobiographical memories of highly positive and highly negative events in their lives. Experiment 1 replicated earlier findings for memories of highly negative events: Central details were recorded more frequently than peripheral details, and a weak correlation was found between emotional intensity and number of central details. In Experiment 2, undergraduates recorded details of memories of both their happiest and their most shocking events. Central details dominated over peripheral details only in memories of shocking events. This finding was replicated in Experiment 3. Recording memory details affected the participants' moods and generated a mood congruence effect in a subsequent recall of word-cued memories. The findings suggest that tunnel memories - enhanced memory for the central details of an event-are limited to emotionally negative memories. The findings contradict expectations derived from the notion of repression.
\end{abstract}

What would you remember from an intensely romantic walk on the beach? The moonlight flickering on the waves, the sounds of the seagulls, the smell of seaweed? Or would you simply remember the person you were with and the highlights of your romantic conversation? Consider another example. What would you remember from a car accident? The headlights of the approaching car? Your maneuvers to avoid it? A scream from your passenger? The sound of the crash? Would you also remember the color of the car, what shoes you were wearing, what you had been talking about right before the accident, or the music that was being played on the radio?

In the present work, the effect of emotional valence on the types of details that are remembered from emotionally arousing events was investigated. Several studies have found that a greater number of central details are remembered from emotionally upsetting events than from neutral events (see Christianson, 1992, and Reisberg \& Heuer, 1992, for reviews), leaving unanswered the question of whether this effect is caused by the intensity of the event or its negative valence. To examine the effect of valence, pleasant and unpleasant memories were compared.

\section{EMOTIONAL AROUSAL, PLEASANTNESS, AND MEMORY}

Most studies on memory and emotion have measured the effect of emotional arousal on memory and have ignored the possible effects of valence or the effects of dis-

The work reported in this article was supported by a grant from the Danish Research Council for the Humanities. Correspondence may be sent to D. Berntsen, Department of Psychology, University of Aarhus, Asylvel 4, 8240 Risskov, Denmark (e-mail: dorthe@ psy.au.dk). crete emotions (Levine, 2002). Also, most studies have measured the effects of emotion on the accuracy of the memory and have tended to disregard other aspects of remembering, such as accessibility, durability, or the quality of reliving an event. For example, studies on memory and learning have often examined whether emotionally arousing material is remembered better than emotionally neutral material. However, in such studies, the emotionally arousing material is typically unpleasant, in addition to being arousing. Thus, it is unclear to what extent the observed effects derive from the arousal associated with the emotional material or from the unpleasantness. This critique applies to classic studies in the eyewitness literature (e.g., Clifford \& Hollin, 1981; Clifford \& Scott, 1978; Loftus \& Burns, 1982) and to most studies on flashbulb memories of shocking public and private events (Brown \& Kulik, 1977; see Conway, 1995, for a review), as well as to many studies addressing the neurobiology of learning (Cahill \& McGaugh, 1998; Cahill, Prins, Weber, \& McGaugh, 1994; Gold, 1987; LeDoux, 1996).

\section{Tunnel Memories and Fear}

Some studies have found that, whereas memory for peripheral details seems to be diminished by high levels of arousal, memory for central details (emotion-related and plot-relevant details) appears to be facilitated (e.g., Burke, Heuer, \& Reisberg, 1992; Christianson \& Loftus, 1991; Christianson, Loftus, Hoffman, \& Loftus, 1991; see Christianson, 1992, for a review). This can be seen as consistent with Easterbrook's (1959) cue utilization hypothesis, according to which the number of cues to which an organism attends decreases monotonically with increasing arousal. Mandler (1975) suggested that not just central details belonging to the external environment, but also details related 
to individuals' inner lives (such as affect and physiological activation) get more attention during high arousal. All of the studies, however, have compared only memory for arousing negative material with memory for emotionally neutral material. Thus, although we can conclude that negative emotional arousal sometimes facilitates memory for central details, we cannot decide the extent to which this effect is due to the arousal or the unpleasantness associated with the to-be-remembered material.

From an evolutionary perspective, one might predict that an individual would concentrate more on central details when he or she is in a state of fear, as compared with a state of intense happiness. A state of fear often requires a fast reaction directed toward the fear-eliciting aspects of the situation, whereas the same is not true for happy events. For example, in a dangerous traffic situation, it would be disastrous to start observing the surroundings, whereas in a state of happiness, it would usually be totally safe to pay attention to parts of the situation other than the parts that elicit the emotion. This assumption is resonant with the notion of tunnel memories as described by Safer, Christianson, Autry, and Österlund (1998). The notion refers to a narrowing of attention and memory so that the most central parts of an emotionally arousing situation are better remembered and the peripheral parts are remembered less well than for a neutral situation. Safer et al. explicitly restrict the notion of tunnel memories to memory for traumatic events or other situations with increased levels of fear and anxiety. Christianson (1992) argued that tunnel memories may mean that more attention, more preattentive processing, and more postevent elaboration are allocated to the central details of emotionally upsetting scenes.

Studies on attention and judgment indicate that negative features generally appear more salient than positive parts of a situation (Taylor, 1991). Lang (1994) argued that negative affect involves a more pronounced startle response than does positive affect. If so, this is likely to instigate more rapid narrowing of attention to focus on the critical details in such events, as compared with emotionally positive events. Öhman, Flykt, and Esteves (2001) found that fear-relevant pictures were identified more quickly than fear-irrelevant ones. They argued that these findings indicate a predisposition for directing attention toward threatening stimuli. Also, the fact that positive affect is generally associated with more elaborate processing (cf. Ashby, Isen, \& Turken, 1999) can be seen to support the assumption that tunnel memories are primarily caused by arousing and unpleasant events.

\section{Repression and Dissociation}

An alternative to the notion of tunnel memory for traumatic events is found in the clinical notions of dissociation and repression. The notion of dissociation is divided into primary, secondary, and tertiary forms. Only the first is relevant here. Primary dissociation refers to a disintegration of the autobiographical memory of the trauma, so that the person's thoughts and his or her verbal description of the trauma memory do not form a coherent narrative (e.g., Nijenhuis \& van der Hart, 1999). Van der Kolk and Fisler
(1995) linked their observation that traumatic memories show incoherence and poor narrative organization to the findings of enhanced memory for central details in unpleasant or fear-provoking scenes, reported earlier. However, van der Kolk and Fisler's interpretation of these findings is questionable, because one operational criterion for central details is relevance for the gist or the plot of the event (Christianson, 1992, p. 291). Thus, fragmented and incoherent narratives of the trauma would be more consistent with a predominance of peripheral (gist-unrelated) details over central (gist-related) details, and not with the reverse, contrary to the empirical evidence.

A dominance of central details in memories of unpleasant events is also counter to the psychoanalytic notion of repression. "The basis for repression itself can only be a feeling of unpleasure," Freud argued (Breuer \& Freud, $1895 / 1953$, p. 116). Modern repression theorists agree (e.g., Davies, 1987). Information connected with the source of intensely negative emotion and/or with the gist of a highly stressful event is almost necessarily unpleasant. Thus, contrary to the findings cited above, central details of negative events should be repressed, not enhanced in memory.

\section{Studies of Autobiographical Memories}

The clinical observations on dissociation and repression disagree with the findings from several laboratory and field studies, which show that the central details of unpleasant, shocking events are remembered better than the peripheral parts (Christianson, 1992). It can be argued, however, that the events or stimulus material used in these laboratory studies have been irrelevant to the life of the person and void of long-term consequences and, therefore, have been unable to match the real-life effects observed in clinical settings.

Very few studies have examined central and peripheral details in memories of autobiographical events that the participants themselves have classified as the most traumatic experiences they have ever had. One exception is Christianson and Loftus (1990), who asked participants to recall their most traumatic memory and rate the content on a series of scales, including estimating the number of central and peripheral details that they thought they could remember. In a second experiment, participants were asked whether one detail was remembered better than the rest and, if so, whether this particular detail was central or peripheral to the event. In both experiments, Christianson and Loftus (1990) replicated the basic finding from the laboratories. They found a positive correlation between the strength of the negative emotion associated with the memory and the number of central details and a negative correlation between the strength of the emotion and peripheral details. Wessel and Merckelbach (1994) replicated Christianson and Loftus's (1990) second experiment, with the same results for central details, but not for peripheral details.

However, the procedure used in these experiments may have been problematic: To ask whether one detail of the memory was remembered particularly well and, if so, whether this detail was central or peripheral may have 
given way to some circular inferences among the participants: If a piece of information seems particularly well remembered, participants may be inclined to deem it central for that very reason (cf. Nisbett \& Wilson, 1977). A different procedure was used in Experiment 1 to overcome this problem.

\section{EXPERIMENT 1}

The main purpose of this experiment was to try to replicate Christianson and Loftus (1990) and Wessel and Merckelbach (1994) by using an alternative procedure for measuring the number of central and peripheral details. Instead of asking participants to estimate the number of remembered details or to decide whether one detail was remembered better than the rest, the participants were here asked to retrieve the target memory and record as many details as possible within a limited period of time. Thus, instead of making assessments about their memory, the participants were asked simply to report the content of their working memory, consistent with Ericsson and Simon (1980). The details were scored afterwards by two independent judges to keep the scoring and the retrieval of details separate.

\section{Method}

Participants. The data collection was carried out as part of an undergraduate course. The participants were 143 first-year psychology students, 116 females and 27 males, with an average age of 24.7 years (range, 18-49).

Procedure. The procedure had four successive steps. First, the participants were asked to review their personal life story for $1 \mathrm{~min}$ and to decide which experience was the most shocking they had ever had. A shocking event was described, consistently with the clinical definition of trauma (cf. American Psychiatric Association, 1994), as an overwhelmingly negative experience associated with unclear thoughts, confusion, fear, and strong feelings of helplessness. Second, the participants wrote a brief description of the content of their most shocking experience within $3 \mathrm{~min}$. Third, the participants introspected the memory image and recorded as many memory details as possible within $5 \mathrm{~min}$. They were instructed to record all kinds of details, even details that appeared insignificant or bizarre. The participants were instructed to number the recorded details in succession. A detail was described as a fragment of the memory that formed a natural unit of information for the participant. Finally, the participants filled out a brief questionnaire in which they were asked to rate qualities and event characteristics associated with the memory. The questions are presented in Table 1.

For ethical reasons, the participants were initially informed that they did not have to participate in the experiment if they found it too intimidating. Also, they were allowed to drop out at any time they wanted to during the experiment. Finally, if a participant wanted to participate but found it too hard to record his or her most shocking event, it was permissible to choose a less provoking memory. Three participants indicated on the questionnaire that their answers were not based on their most shocking events.

Scoring of details. Details were classified as central or peripheral and as internal or external by two independent judges. A detail was classified as central if (1) it was related to what was shocking to the person in the remembered event and if (2) it could not be left out or replaced without a major change in the content of the event. Otherwise, it was classified as peripheral. A detail was classified as internal if it referred to a physiological or mental state that could not be clearly perceived by anyone other than the person him- or herself. Otherwise, it was classified as external (e.g., "I felt sad" was an internal detail, whereas "I was screaming" was external). The two judges agreed in $86 \%$ of the cases on the distinction between central and peripheral details and in $93 \%$ of the cases in relation to internal versus external details. Disagreement was solved by discussion. Only a few cases were deemed unclassifiable on each of the two dimensions.

\section{Results}

The data analyses (to be presented in this and the subsequent studies) are not broken down by gender, because

Table 1

Experiment 1: Means, Standard Deviations, and Correlations With Proportions of Central Details

\begin{tabular}{lrrr}
\hline \multicolumn{1}{c}{ Characteristic } & $M$ & $S D$ & $r$ \\
\hline 1. Number of recorded details? & 13.51 & 6.39 & -.15 \\
2. How many years since the event? & 5.52 & 6.49 & -.07 \\
3. How surprising was the event? & 5.67 & 1.36 & .09 \\
4. Did the event have long-term consequences? & 4.34 & 1.81 & -.05 \\
5. How emotionally intense was the event at the time? & 5.98 & 1.02 & $.18^{*}$ \\
6. How emotionally intense is the event at recall? & 4.05 & 1.62 & -.08 \\
7. How emotionally negative was the event at the time? & 5.81 & 1.44 & .14 \\
8. How emotionally negative is the event at recall? & 4.36 & 1.81 & .01 \\
9. How vivid is your memory? & 5.37 & 1.28 & -.05 \\
10. How important was the event at the time? & 6.15 & 1.38 & -.02 \\
11. How often have you talked about the event? & 4.14 & 1.66 & $.19 *$ \\
12. Has the memory come unbidden to you: & & & \\
a. Immediately after the event? & 4.42 & 1.58 & $-.22 *$ \\
b. During the most recent month? & 2.16 & 1.19 & -.04 \\
\hline
\end{tabular}

Note-Scales for Questions 3-12: (3) $1=$ didn't surprise me at all, $7=$ no other event has surprised me this much; (4) $1=$ no consequences at all, $7=$ no other event has had so many consequences; (5) $1=$ no detectable emotion, 7 = the most intense experience I have ever had; (6) 1 = no detectable emotion, 7 = the most intense experience I have ever had; (7) 1 = no detectable negative emotion, 7 = the most negative experience I ever had; (8) 1 = no detectable negative emotion, 7 = the most negative experience I ever had; (9) $1=$ cloudy and imageless, $7=$ as clear and vivid as if experienced again $;(10) 1=$ insignificant, $7=$ more important than anything else; (11) $1=$ never, $7=$ more than any other experience in my life; (12) $1=$ never, $2=$ only once, $3=$ a few times a month, $4=$ a few times $a$ week, $5=$ a few times a day, $6=$ many times $a$ day. $N \mathrm{~s}=141-143$. $* p<.05$. 
no hypotheses about gender differences can easily be derived from the literature on central and peripheral details in emotional memories. Also, the population consisted of four times more females than males and was not suitable for explorative analyses on this topic.

Most of the recorded memories dealt with experiences of loss of a loved one (25\%) or accidents (24\%). Several memories dealt with violence and aggressive episodes $(10 \%)$, with seriously failing to satisfy one's own ambitions or other people's expectations (10\%), or with being let down and disappointed by trusted people (10\%). A few memories dealt with experiences of sudden and intense anxiety, such as nightmares or fear of heights (6\%), episodes related to physical disease (5\%), parents' divorce (4\%), or sexual abuse ( $2 \%)$. A few dealt with other shocking events (4\%). This appears to be similar to the types of events reported in Christianson and Loftus (1990) and in Wessel and Merckelbach's (1994) study.

The memories referred to events that were rated as both highly negative and highly intense at the time when they took place (see Table 1). The number of recorded details varied from 4 to 46 . This variability seemed to derive primarily from differences between participants as to how thoroughly they described the details. Some used many words in describing what they classified as one single detail, whereas other participants used a telegraphic writing style, which enabled them to record more details within the time limit. This variability was countered by the use of proportions calculated within each participant in the statistical analyses in the present and the two subsequent experiments. (Analyses based on the raw numbers yielded the same main findings.) The choice of proportions is consistent with the notion of tunnel memories (Safer et al., 1998). What is critical in relation to this notion is the number of central details relative to the total number of details recorded for each memory, since this measure indicates the degree to which memory is focused on the central parts of the event.

A clear dominance of central details was found. The mean proportions of central and peripheral details were .75 versus $.23[t(142)=17.61, p<.001]$. Also, external details dominated over internal details [mean proportions were .61 vs. $.38 ; t(142)=6.45, p=.001]$. Table 1 presents all correlations with central details. How frequently the participants had talked with other people about the event and the intensity experienced at the event correlated weakly, but significantly, with proportion of central details, and a negative correlation was found with frequency of intrusive memories in the time after the event. Proportion of internal details correlated only with event age $[r(138)=-.27, p<.05]$. Naturally, several of the included rating variables correlated with one another. A correlation matrix is available in the Appendix.

\section{Discussion}

Central details dominated over peripheral details. Intensity of emotion was weakly (but significantly) correlated with the proportion of central details. Thus, the present study replicates Christianson and Loftus's (1990) and Wessel and Merckelbach's (1994) finding that the fre- quency of central details in autobiographicalmemories of traumatic experiences correlates with emotion at the event. Also in these previous studies, only weak correlations ( $r=.36$ and $r=.28$, respectively) were obtained.

In addition, proportion of central details correlated positively with how frequently the participants had talked about the event. One likely explanation is that central, rather than peripheral, details are rehearsed in conversations owing, among other things, to conversational maxims (Grice, 1989). In contrast, a negative correlation existed between central details and frequency of intrusive memories in the time immediately after the event. However, since the proportions of central and peripheral details are almost complementary here, this finding is best explained as a result of a weak positive correlation between ratings of intrusions and proportion of peripheral details $[r(138)=.17, p<.05]$, indicating that intrusive memories help to keep peripheral details accessible by rehearsing them.

The present experiment failed to show any relation between measures of emotion and whether the remembered details referred to features from the external world or to participants' internal physiological and emotional states during the event. Thus, if attention tends to be turned inward under high emotional arousal (Mandler, 1975), apparently this was not reflected in the memory representations. Only event age correlated significantly (and negatively) with number of internal details, indicating that internal details are more rapidly forgotten than details about the external parts of the event. One possible explanation is that internal details are less imageable than external details and, thus, more difficult to retain (cf. Rubin, 1995), or they are less likely to be rehearsed in conversations, because they are considered as less relevant than the objective facts of the event.

One problem with both the present experiment and the previous experiments it replicated is that the scale for emotion does not capture the full range of the valence dimension, since it included only degrees of unpleasantness. Thus, it is not clear whether the results from the present and previous experiments also speak to memories of emotionally arousing positive events. Experiment 2 was conducted to address this question.

\section{EXPERIMENT 2}

The purpose of the present experiment was to investigate the effect of emotional valence on the accessibility of central and peripheral details. According to the notion of tunnel memories (Safer et al., 1998), we should expect central details to dominate in memories for situations with increased levels of fear and anxiety, relative to memories of positive events. Alternatively, according to the notions of repression and dissociation, central details in memories of unpleasant events would be associated with unpleasant emotion, so that they should be harder to remember than central details for pleasant events. Thus, we should expect central details to be more dominant in memories of highly happy events than in memories of highly shocking events, according to this assumption. To investigate this possibil- 
ity, the participants in Experiment 2 were asked to record details for memories of both their most shocking and their happiest events. A neutral condition was not included, because it was considered impossible to have neutral memories that would match memories of most shocking and happiest events on such possible confounding variables as intensity, importance, and frequency of rehearsal.

Experiment 1 established that the two independent judges' scoring of details led to essentially the same findings as those in the previous studies by Christianson and Loftus (1990) and Wessel and Merckelbach (1994), for which reason it was decided now to return to the less time consuming method of having participants themselves score their details. In doing so, the participants were provided with the same operationalizations as those used by the two judges in Experiment 1, which seems to be an improvement of the self-scoring method. To simplify the procedure, it was decided to leave out the scoring of internal versus external details, because this variable is not central to the notion of tunnel memories and because Experiment 1 showed no relation between internal versus external details and emotionality.

\section{Method}

Participants. The data collection was carried out as part of an undergraduate course. The participants were 114 psychology students, 89 females and 25 males, with an average age of 27.4 years (range, 21-55).

Design and Procedure. The participants were randomly assigned to two groups. Both groups recorded details and answered a series of questions related to memories of their most shocking and most happy experiences, in counterbalanced order. The procedure was essentially the same as the one described in Experiment 1, with the exception that each participant classified his or her own recorded details as peripheral, central, or unscorable. The operationalization of central and peripheral details was carefully explained and exemplified for the participants before they carried out the task. After scoring the details, the participants filled out a brief questionnaire addressing memory qualities and event characteristics of the target memory. The content of this questionnaire was the same as that in Experiment 1, with the exception that rating of negative emotion was left out.

After a 15-min pause, the same procedure was carried out for memories at the opposite pole of the valence scale. The participants who ended the study by recording the memory of their most shocking events were provided the opportunity to stay back and chat with the experimenter, so that they did not leave the laboratory strongly influenced by the unpleasant emotions associated with the memory.

\section{Results}

The reported memories could be sorted into relatively few classes of events. Table 2 shows their frequencies. As in Experiment 1, memories for the most shocking events dealt predominantly with losses of loved ones and with accidents. The top scores on the list for happiest events were experiences of falling in love and achievements in education and sports.

The main findings are shown in Table 3. An equal number of details was recorded in relation to the two types of memories; however, significantly more central details were recorded in relation to memories for shocking events, as compared with happy memories. Moreover, a significant overweighting of central details (relative to peripheral de- tails) was found in memories for the participants' most shocking events $[M \mathrm{~s}=.54$ vs. $.42 ; t(111)=3.02, p<$ $.005]$, but not in memories for the happiest experiences. In fact, for the latter, a slight (and insignificant) dominance of peripheral details was found $[M \mathrm{~s}=.46 \mathrm{vs} . .50$; $t(113)=1.07, p=.3]$. The dominance of central details for memories of the most shocking event was consistent across the participants, in that proportions of central details were higher in 73 out of 112 cases ( 2 cases were missing). For memories of happiest events, a dominance of central details was found only in 54 out of 114 cases $\left[\chi^{2}(1)=7.28, p<.01\right]$.

A two-way analysis of variance, with group (presentation order) as the between-subjects variable and proportion of central details for positive and negative memories included as a repeated measures variable with two levels, showed a clear main effect for type of remembered event on proportion of central details $\left[F(1,110)=10.2, M S_{\mathrm{e}}=\right.$ $0.04, p<.005]$ and an interacting group effect $[F(1,110)=$ $\left.5.3, M S_{\mathrm{e}}=0.04, p<.05\right]$. A dominance of central details for memories of shocking events was found only for the group who recorded the negative memory second $[M \mathrm{~s}=$ .55 (shocking) vs. .40 (happy); $t(53)=3.76, p<.001]$. This dominance was not found in the group who recorded their happiest memory second $[M \mathrm{~s}=.52$ (shocking) vs. .50 (happy); $t(59)=0.66, p=.5]$. Overall, the participants recorded fewer central details to their first memory than to their second memory $[M \mathrm{~s}=.46$ vs. $.52 ; t(111)=$ $2.04, p<.05]$. This indicates the influence of some demand characteristics: After learning about the distinction between central and peripheral details, the participants may have become more inclined to record the former type, irrespective of whether the memory referred to a shocking

Table 2

Experiment 2: Reported Memories of Shocking and Happy Events

\begin{tabular}{lrr}
\hline \multicolumn{1}{c}{ Events } & Frequency & Percent \\
\hline Shocking & 30 & \\
Losses of loved ones & 26 & 26.5 \\
Accidents & 17 & 23.0 \\
Episodes related to physical disease & 15 & 15.0 \\
Let down and disappointed by trusted people & 6 & 5.3 \\
Failing to satisfy ambitions/expectations & 5 & 4.4 \\
Violence and aggression & 4 & 3.5 \\
Sudden and intense fear (e.g., anxiety attacks) & 3 & 2.7 \\
Sexual abuse & 1 & 0.9 \\
Divorce of parents & 6 & 5.3 \\
Other & 113 & 99.9 \\
Total* & 34 & \\
Happy & 30 & 29.8 \\
Falling in love & 15 & 26.3 \\
Achievements in education and sports & 13.2 \\
Being pregnant or birth of child & 10 & 8.8 \\
Big moments and celebrations in family & 7 & 8.8 \\
Episodes in relation to self-development & 6.1 \\
Beautiful scenery & 3 & 2.6 \\
Manifestations of friendship & 2 & 1.8 \\
Religious experiences & 3 & 2.6 \\
Other & 114 & 100.0 \\
Total &
\end{tabular}

*One missing case is left out. 
Table 3

Experiment 2: Mean Scores for Memories of Most Shocking and Most Happy Events

\begin{tabular}{|c|c|c|c|c|c|}
\hline \multirow[b]{2}{*}{ Characteristic } & \multicolumn{2}{|c|}{ Shocking } & \multicolumn{2}{|c|}{ Happy } & \multirow[b]{2}{*}{$t(111-113)$} \\
\hline & $M$ & $S D$ & $M$ & $S D$ & \\
\hline Number of details & 13.69 & 6.74 & 13.98 & 6.34 & 0.48 \\
\hline Proportion of central details & 0.54 & 0.22 & 0.46 & 0.22 & $3.02 * *$ \\
\hline Years since event & 6.46 & 6.43 & 3.95 & 3.79 & $4.03 * * *$ \\
\hline Surprise & 6.15 & 1.20 & 4.44 & 1.85 & $8.87 * * *$ \\
\hline Consequences & 4.74 & 1.75 & 5.31 & 1.68 & $2.60 * *$ \\
\hline Intensity then & 6.25 & 1.02 & 6.08 & 0.90 & 1.33 \\
\hline Intensity now & 4.68 & 1.65 & 4.74 & 1.47 & 0.32 \\
\hline Vividness & 5.40 & 1.22 & 5.32 & 1.35 & 0.53 \\
\hline Importance & 6.17 & 1.25 & 6.28 & 0.96 & 0.77 \\
\hline Talked about & 4.43 & 1.63 & 4.02 & 1.72 & 1.86 \\
\hline Intrusions then & 5.05 & 1.18 & 4.87 & 1.22 & 1.33 \\
\hline Intrusions now & 2.35 & 1.19 & 2.38 & 1.32 & 0.23 \\
\hline
\end{tabular}

$* * p<.01 . \quad * * * p<.001$.

or a happy event. To control for this effect, a $t$ test was conducted based on only the first memories recorded in each of the two groups. This analysis showed a significant difference between the proportions of central details for memories of most shocking and happiest events $[M \mathrm{~s}=$ .53 vs. .40, respectively; $t(110)=2.96, p<.005$ ], thus confirming the main results.

Table 3 shows some additional differences between the two types of memories. Memories for shocking events were older and had higher scores on surprise and consequences than did memories of happy experiences. For shocking events, the proportion of central details did not correlate significantly with any of the rating variables included in Table 3 ( $r$ s ranged from .00 to .16). For memories of happiest events, weak, but significant, correlations were found between the proportion of central details and the ratings of surprise $[r(111)=.19, p<.05]$, intensity then $[r(114)=.24, p<.05]$, and intensity at retrieval $[r(111)=.19, p<.05]$. No differences were found on the remaining variables in Table 3. Interestingly, the two classes of events were associated with similar frequencies of intrusive (or involuntary) memories (cf. Berntsen, 1996; Brewin, Christoulides, \& Hutchinson, 1996).

To summarize, the results showed a dominance of central details for memories of the most shocking events, but not for the memories of the happiest events. Memories for shocking events were older than memories of happy experiences. This can be seen as consistent with the view that intense negative emotion at encoding helps to keep memories accessible for an extended amount of time (LeDoux, 1996). The shocking events were rated as more surprising, which may be seen as consistent with the idea the people generally hold positive expectations for themselves and the world and do not expect highly negative events to take place in their lives (Janoff-Bulman, 1988). The participants' happiest experiences were rated as more consequential than their most shocking events. One possible explanation is that happy events need to have distinct consequences to be maintained in memory for a very long time. The proportion of central details did not correlate with event age or consequentiality for either type of memories. Surprise correlated with central details, but only for happy memories. Thus, the differences reported in Table 3 on these measures were unrelated to the observed differences on central details.

The findings support the notion of tunnel memories for stressful events and contradict the idea that the most unpleasant parts of traumatic and fear-eliciting events are repressed and, thus, hard, if not impossible, to retrieve. It is, of course, impossible to decide whether the participants had repressed memories of experiences in their past that were even more shocking than the ones they reported here. A different and more relevant question in relation to the idea of repression is the extent to which the reported memories were connected with unpleasant emotion at retrieval. A memory of an unpleasant event that involves no reliving of the unpleasant emotions at the time of retrieval should not instigate repression of even the most emotionrelevant aspects of the remembered situation, according to Breuer and Freud (1895/1953), who stated that: "The basis for repression itself can only be a feeling of unpleasure" (p. 116, my emphasis). Thus, if the memories of shocking events recorded in the present study had lost their ability to affect the participantsemotionally, they would not be expected to instigate repression of the emotionrelated, central details. Thus, it is important to examine whether the memories - and the very act of recording them-influenced the participants emotionally.

To investigate this possibility, a third experiment was conducted. This experiment included three different measures of emotional impact: (1) self-reported mood states before and after the memory task, (2) remember/know judgements of emotion associated with the target memory (Gardiner \& Java, 1993; Oschner, 2000; Tulving, 1985), and (3) a mood congruence experiment.

\section{EXPERIMENT 3}

To measure the emotional impact exerted by the recording of the target memory and to avoid the possible demand characteristics mentioned in Experiment 2, each participant recorded only one memory, either their most shocking or their most positive event. They indicated whether they remembered or knew the emotions associated with the event, and they rated their mood before and after the recording. After the recording of the target memory, the participants took part in a mood congruence experiment. The purpose was to examine whether the recording of the target memory and its details had affected the participant's emotional state to such an extent that this would generate a mood congruence effect in the recording of a series of word-cued memories-that is, recall biased in favor of memories emotionally consonant with the current mood (e.g., Eich, 1995). If the recording of emotional memories would be able to impact the participants' emotional state to the extent that this would bias subsequent recall in favor of emotionally congruent memories, this would indicate that emotions associated with the target memory were, in 
fact, relived at retrieval. If so, central details of the negative memories should be diminished rather than enhanced in memory, according to the notion of repression The reverse pattern would be expected according to the notion of tunnel memories.

\section{Method}

Participants. One hundred and thirteen psychology students (92 females and 21 males; mean age, 26.7 years; range, 21-52) participated as part of an undergraduate course.

Design and Procedure. The participants were randomly assigned to two groups. One group recorded as many details as possible and answered a series of questions for memories of their most shocking event. The other group did the same for memories of their most happy event.

The procedure had two parts. The first part was largely identical to Experiments 1 and 2. The second part was a mood congruence experiment. The specific steps of the two parts of the procedure are as follows.

Part One. The participants were asked to rate their mood on a 5point scale $(2=$ very good, $1=$ good, $0=$ neutral or mixed, $-1=$ bad, $-2=$ very $b a d)$. The participants then reviewed their personal life for $1 \mathrm{~min}$ and decided which experience was the most shocking/ happiest one they had ever had. They introspected the memory of their most shocking/happiest experience and recorded as many memory details as possible within $5 \mathrm{~min}$, after which they scored the details as described in Experiment 2. The participants then filled out a brief questionnaire that was similar to the one described in Experiment 1 (see Table 1), with the following exceptions. Frequency of intrusive memories about the event was rated on a 7-point scale $(1=$ never, $7=$ very often $)$. The participants were asked whether they remembered their original emotions (by reexperiencing them at retrieval) or whether they merely knew which emotions they had experienced at the original event $(1=\mathrm{I}$ remember/reexperience my emotions, 2 = I know how my emotions were at the time but do not reexperience them).

Part Two. This part was carried out immediately after Part One. The participants were asked to rate their mood again on a 5-point scale similar to that described in Part One. The participants then recorded autobiographical memories to five neutral Danish word cues (in an English translation: telephone, choice, hike, bowl, and view). Each word cue was presented on a separate page in their booklets. The participants were given 1 min for each memory. After the recording of all five cue word memories, they rated the valence and the intensity of each of the recorded cue word memories on 7-point scales similar to the ones described in Experiment 1, and they specified the event age, in years, of each of the cue word memories.

\section{Results}

The present experiment replicated the finding in Experiment 2 (see Table 4): An equal number of details was recorded to both types of memories, but significantly more central details were recorded to memories of most shocking events than to memories of the happiest events. Furthermore, as in Experiment 2, a significant overweighting of central details was found in memories for shocking events $[M \mathrm{~s}=.58$ vs. $.39 ; t(56)=4.01, p<$ $.001]$, but not in memories for happy experiences $[M \mathrm{~s}=$ .48 vs. $.49 ; t(55)=0.27, p=.8]$. The dominance of central details for memories of shocking events was consistent across participants. Among the 57 participants who recorded details of memories of their most shocking event, 42 recorded a greater number of central than of pe- ripheral details. Among the 56 participants who recorded details of their happiest memory, only 28 recorded a greater number of central than of peripheral details $\left[\chi^{2}(1)=\right.$ $6.72, p<.01]$.

Consistent with Experiment 2, memories of the most shocking events were older than memories of the happiest events, the shocking events were rated as more surprising than the happy events, and the happy events had had more long-term consequences than did the shocking events (see Table 4). The events were rated as highly negative and highly positive, respectively - that is, both at the extremes of the scale. Also consonant with Experiment 2, the two types of memories did not differ on any of the other variables included in the questionnaire.

For each type of memory, it was explored whether proportion of central details correlated with the rating variables included in Table 4. For memories of shocking events, proportions of central details correlated significantly only with consequences $[r(57)=.32, p<.05]$. For memories of happiest events, proportion of central details did not correlate significantly with any of the rating variables in Table 4 ( $r$ s ranged from .01 to .23). Thus, the differences between the two types of memory on event age, surprise, and consequences (see Table 4) appeared to be unrelated to the observed differences on central details.

Emotional impact exerted by the memories. As is shown in Table 4, no difference was found on the frequency of remember versus know judgments on the emotional content between the two types of memories. For both, the proportion of remember responses was significantly higher than the proportion of know responses ( $p$ s $<.01)$, indicating that the majority of the participants relived the emotion associated with the remembered event while recording the memory. Another measure of emotional impact was obtained by comparing the first mood rating on the -2 - to 2-point scale with the one that was made immediately after the participants had recorded the target memory and determining whether the mood had changed. A significant change in emotional state was ob-

Table 4

Experiment 3: Mean Scores for Memories of Most Shocking and Most Happy Events

\begin{tabular}{|c|c|c|c|c|c|}
\hline \multirow[b]{2}{*}{ Characteristic } & \multicolumn{2}{|c|}{ Shocking } & \multicolumn{2}{|c|}{ Happy } & \multirow[b]{2}{*}{$t(110-111)$} \\
\hline & $M$ & $S D$ & $M$ & $S D$ & \\
\hline Number of details & 15.63 & 6.19 & 14.80 & 4.78 & 0.79 \\
\hline $\begin{array}{l}\text { Proportion of } \\
\text { central details }\end{array}$ & 0.58 & 0.20 & 0.47 & 0.20 & $2.90 * *$ \\
\hline Years since event & 6.02 & 6.87 & 3.03 & 3.32 & $2.91 * *$ \\
\hline Surprise & 6.00 & 1.18 & 4.16 & 1.78 & $6.47 * * *$ \\
\hline Consequences & 4.64 & 1.76 & 5.53 & 1.39 & $2.97 * *$ \\
\hline Valence & -2.43 & 0.74 & 2.32 & 0.58 & $38.08 * * *$ \\
\hline Intensity & 6.26 & 0.74 & 6.07 & 0.85 & 1.28 \\
\hline Vividness & 5.19 & 1.42 & 5.50 & 0.93 & 1.36 \\
\hline Importance & 6.32 & 1.02 & 6.16 & 0.95 & 0.86 \\
\hline Talked about & 3.98 & 1.63 & 3.91 & 1.51 & 0.24 \\
\hline Intrusions & 4.28 & 1.66 & 4.91 & 1.47 & 1.47 \\
\hline Remember/know & 0.63 & 0.49 & 0.71 & 0.46 & 0.93 \\
\hline
\end{tabular}

$* * p<.01 . \quad * * * p<.001$. 
tained among the participants who had recorded a memory of their most shocking event. Their mean ratings were initially .86 versus .15 at the second time $[t(56)=6.12$, $p<.0001]$. For the happy memory group, the same measures were 1.00 versus $.88[t(55)=1.55, p=.13]$. Apparently, when looking at the means, only the recording of the most shocking memory had been able to cause a detectable change in the participants' moods.

More nuances (but basically the same picture) appear when we look at the individual movements from the first to the second mood rating. Among the participants who had recorded the memory of their most shocking event, 35 had less positive ratings the second time, 20 stayed the same, and 3 rated the second mood as more positive. For the group who recorded their happiest memories, 14 had less positive ratings the second time, 35 stayed the same, and 7 rated their second mood as more positive. The difference between the two groups on the number of participants whose mood had moved in a positive versus negative direction was significant $\left[\chi^{2}(1)=6.22, p<.05\right]$.

As is shown by the means of the first mood score, both groups were, on average, in a moderately good mood when they entered the experiment. During a relatively uneventful data collection, it is presumably easier to change a moderately good mood into a neutral mood than it is to change a moderately good mood into a very good mood. This may explain why recording memories of the happiest events changed only a few of the participants' mood states in the expected direction and the great majority in this group stayed at the same (happy) level, whereas recording memories of the most shocking event did make many of the participants' moods less positive. At any rate, a significant correlation was obtained between the valence ratings of the target memory and the participants' second ratings of their moods [Spearman's $R(112)=.47, p<$ $.0001]$, but not between valence ratings and the first mood ratings $[R(112)=.17, p=.07]$, which seems to document the mood effect of the intervening memory task.

A mood congruence effect was found on the emotional content of the word-cued memories. First, a significant correlation was found between the second mood rating and the ratings of valence averaged for all five word-cued memories $[r(89)=.40, p<.0001]$. Second, the proportion of word-cued memories rated as positive $(>0$ on the -3 to 3 scale) was smaller for the participants who had recorded their most shocking memory than for the participants who initially recorded their most happy memory $[M \mathrm{~s}=.55$ vs. $.65 ; t(111)=2.72, p<.01]$. In contrast, the former rated a higher proportion of their word-cued memories as emotionally negative ( $<0$ on the -3 to 3 scale) than did the latter $[M \mathrm{~s}=.27$ vs. $.20 ; t(111)=2.14, p<$ $.05]$. The proportion of neutral memories $(=0$ on the -3 to 3 scale) did not differ $[M \mathrm{~s}=.18$ vs. $.14 ; t(111)=1.00$, $p=.3]$. The interaction between group and proportions of positive, negative, and neutral word-cued memories was significant $\left[F(2,222)=4.76, M S_{\mathrm{e}}=0.05, p<.01\right]$. The mood congruence effect was asymmetrical, in that more positive than negative memories were recorded for both groups $\left[F(1,111)=115.24, M S_{\mathrm{e}}=0.06, p<.0001\right]$. This asymmetry is in agreement with findings from many other studies on the relation between mood states and memory (see Eich, 1995; Eich \& Macaulay, 2000; Eich, Macaulay, \& Ryan, 1994). It may reflect a general dominance of positive events in autobiographical memory (e.g., Thompson, Skowronski, Larsen, \& Betz, 1996), which is reduced (but not removed) in a negative mood state. A complementary explanation is that the retrieval of positive memories serves as a way of repairing mood among participants who are assigned to a negative mood induction (e.g., Isen, 1985; Josephson, Singer, \& Salovey, 1996).

To summarize, Experiment 3 replicated the findings from Experiment 2. Central details dominated over peripheral details in the memories of the most shocking events, but not in the memories of the happiest experiences. Memories of the most shocking experiences were older than memories of the happiest events and were also rated as more surprising. None of these variables were found to correlate with the number of central details for either of the two classes of memories and can thus be ruled out as possible confounders. As in Experiment 2, the happiest events were rated as more consequential than the shocking events. Consequentiality correlated with central details for shocking events only. Ratings of intensity, importance, vividness, frequency of intrusions, and rehearsal did not differ. Taken together, the findingsindicate that the number of central details differed as a function of the valence of the memories.

The recording of the memories of the most shocking events was able to color the participants' emotional states. First, the self-reported mood states were significantly less positive after the recording of the target memory than before the recording began among the participants who recorded a memory about their most shocking experience. Second, the subsequent retrieval of word-cued memories showed a mood congruence effect, so that these participants recorded significantly fewer positive and a greater number of negative memories than did the participants who had previously recorded their happiest memory. This effect is robust, since it usually takes a continuous manipulation to exert a mood impact that is able to cause a mood congruence effect. One successful procedure is to have participants listen to lively or sad music while thinking either elating or depressing thoughts (Eich, 1995). For this procedure to cause a mood congruence effect, the music is played also during the retrieval of the word-cued memories. In the present study, however, a mood congruence effect was obtained simply by having the participants record details of memories of either highly shocking or highly happy events several minutes before the retrieval of the word-cued memories began and without the participants knowing that they were taking part in a mood congruence experiment. In short, the memories of the most shocking events appeared still to be associated with considerable unpleasantemotion at retrieval. Following the notion of dissociation or repression, we should therefore expect the most central (and thus, the most emotion-related 
and plot-relevant details) to be harder to access than the peripheral details, contrary to the present results. Consequently, the results contradict notions of repression and dissociation and support the idea of tunnel memories for highly shocking events.

\section{GENERAL DISCUSSION}

The present work demonstrated a dominance of central details for autobiographical memories that the participants themselves considered to be dealing with their most shocking past event, whereas such tunnel memories were not found for the participants' memories of their happiest events. Because earlier studies have found a similar difference between memory for negative arousing and neutral events (Christianson, 1992), the present findings indicate that tunnel memories are due to the combined effects of high arousal and negative valence, whereas high positive arousal (as during extremely happy events) is not able to create the effect.

The findings contradict the idea that the most unpleasant parts of threatening and/or traumatic scenes are subject to dissociation and/or repression. Exactly the opposite seems to be the case: The emotion- and gist-related details are the parts that are most accessible in the recollection of stressful events. Experiment 3 showed that this was true, even though the recording of the negative memory instigated a measurable deteriorating effect on participants' moods that was strong enough to cause a mood congruence effect in a subsequent retrieval task.

The present findings are concerned with the phenomenology of personal memories, not with their accuracy. As is often the case in studies of autobiographical memory, it is not possible here to corroborate the recorded details with information about the original events. This is a consequence of using memory data from personal events chosen by the participants themselves as the most shocking and happiest ones they had ever encountered. This seemed like a relevant thing to do here, because both the notion of repression and the distinction between central and peripheral details used in the definition of tunnel memories ultimately refer to how an individual subjectively experiences an emotional situation in his or her life. Both repression and tunnel memories center on which parts of a stressful situation especially trigger an individual's emotions. Both notions are thus concerned with the phenomenology of attention and memory.

The findings from Experiments 2 and 3 dealt with the accessibility of details that the participants themselves classified as either central or peripheral in accordance with the same operationalization as that used in Experiment 1 . The proportion of central details for both classes of memories was smaller in Experiments 2 and 3 than in Experiment 1, which suggests that the participants' own classifications of central details were less inclusive than the ones provided by the two independent judges in Experiment 1 .

In Experiments 2 and 3, memories of negative events were considerably older than memories of positive events.
This agrees with Berntsen's (2001) findings on undergraduates' memories for traumatic events and peak experiences. However, in a survey study of a representative sample of the Danish population, Berntsen and Rubin (in press) found this pattern only for the younger age groups (between 20 and 40 years).

Emotion can be seen to vary on several dimensions in addition to valence and arousal. The present study does not rule out the possibility that other dimensions may be important in relation to memory for details. For example, for theorists who argue for the existence of basic emotions - that is, emotions with innate neural substrates, innate facial expressions, and distinct feeling states (e.g., Ekman, 1992; Izard, 1992; Panksepp, 1992)_a distinction between basic and complex emotions might be crucial for memory of details, in that only basic emotions may involve rapid, preattentive processing of the emotioneliciting details (see Öhman et al., 2001, for such a view in relation to fear).

In an appraisal account of emotion (e.g., Lazarus, 1991), on the other hand, each distinct emotion is characterized by a certain appraisal pattern-for example, sadness is characterized by the perception of a irrevocable loss. Following this account, what is central or peripheral for a certain emotional reaction varies as a function of the cognitive appraisal that leads to the reaction. In this view, the extent to which the person focuses on the central details would vary as a function of both the nature of the emotional situation and the coping strategies that person uses to deal with it.

Although the main focus here has been on the frequency of central details, we should not overlook that a substantial number of peripheral details were recorded in all three experiments. Only in memories of the shocking events did the proportion of central details exceed the proportion of peripheral details. The findings therefore show that autobiographical memory is far from limited to those parts of our experiences that are critical for our narratives or our emotions. We remember a considerable number of apparently irrelevant details of our emotional experiences. This was one of the main points of Brown and Kulik (1977) when they introduced the notion of flashbulb memories. The possible functions of such apparently irrelevant memory details have been discussed (see, e.g., Pillemer, 1992)

According to the present results, more than half of the details that we remember from highly happy events are unrelated to the gist of the event and to the experienced emotion. This amount is reduced substantially in memories of highly shocking events. Whether a similar reduction of peripheral details is found in autobiographicalmemories for experiences colored by other negative emotions, such as anger or jealousy, or whether it really is an effect exclusively related to fear and trauma, as has been argued by Safer et al. (1998), is a question for future research.

\section{REFERENCES}

American Psychiatric Association (1994). Diagnostic and statistic manual of mental disorders (4th ed.). Washington, DC: Author.

Ashby, F. G., Isen, A. M., \& Turken, A. U. (1999). A neuropsycho- 
logical theory of positive affect and its influence on cognition. Psychological Review, 106, 529-550.

BERNTSEN, D. (1996). Involuntary autobiographical memories. Applied Cognitive Psychology, 10, 435-454.

BERNTSEN, D. (2001). Involuntary memories of emotional events: Do memories of traumas and extremely happy events differ? Applied Cognitive Psychology, 15, 135-158.

Berntsen, D., \& Rubin, D. C. (in press). Emotionally charged autobiographical memories across the lifespan: The recall of happy, sad, traumatic, and involuntary memories. Psychology of Aging.

Breuer, J., \& Freud, S. (1953). Studies on hysteria. In J. Strachey (Ed.), The standard edition of the complete psychological work of Sigmund Freud (Vol. 2). London: Hogarth Press. (Original work published 1895)

Brewin, C. R. Christoulides, J., \& Hutchinson, G. (1996). Intrusive thoughts and intrusive memories in a nonclinical sample. Cognition \& Emotion, 10, 107-112.

Brown, R, \& Kulik, J. (1977). Flashbulb memories. Cognition, 5, 73-99.

Burke, A., Heuer, F., \& Reisberg, D. (1992). Remembering emotional events. Memory \& Cognition, 20, 277-290.

Cahill, L., \& McGaugh, J. L. (1998). Mechanisms of emotional arousal and lasting declarative memory. Trends in Neurosciences, 21, 294-299.

Cahill, L., Prins, B., Weber, M., \& McGaugh, J. L. (1994). BeTAadrenergic activation and memory for emotional events. Nature, 371, $702-704$.

Christianson, S.-Å. (1992). Emotional stress and eyewitness memory: A critical review. Psychological Bulletin, 112, 284-309.

Christianson, S.-A., \& LofTus, E. F. (1990). Some characteristics of people's traumatic memories. Bulletin of the Psychonomic Society, 28, 195-198.

Christianson, S.-Å., \& Loftus, E. F. (1991). Remembering emotional events: The fate of detailed information. Cognition \& Emotion, 5, 81 108.

Christianson, S.-̊̊, Loftus, E. F., Hoffman, H., \& Loftus, G. R. (1991). Eye fixation and memory for emotional events. Journal of Experimental Psychology: Learning, Memory, \& Cognition, 17, 693701.

Clifford, B. R., \& Hollin, C. R. (1981). Effects of the type of incident and the number of perpetrators on eyewitness memory. Journal of Applied Psychology, 66, 364-370.

Clifford, B. R, \& ScotT, J. (1978). Individual and situational factors in eyewitness testimony. Journal of Applied Psychology, 63, 352-359.

Conway, M. A. (1995). Flashbulb memories. Hove, U.K.: Erlbaum.

DAVIES, P. J. (1987). Repression and the inaccessibility of affective memories. Journal of Personality \& Social Psychology, 53, 585-593.

EASTERBROOK, J. A. (1959). The effect of emotion on cue utilization and the organization of behavior. Psychological Review, 66, 183-201.

EICH, E. (1995). Searching for mood dependent memory. Psychological Science, 6, 67-75.

Eich, E., \& Macaulay, D. (2000). Are real moods required to reveal mood-congruent and mood-dependent memory? Psychological Science, 11, 244-248.

Eich, E., Macaulay, D., \& Ryan, L. (1994). Mood dependent memory for events of the personal past. Journal of Experimental Psychology: General, 123, 201-215.

Ekman, P. (1992). Are there basic emotions? Psychological Review, 99, 550-553.

Ericsson, K. A., \& Simon, H. A. (1980). Verbal reports as data. Psychological Review, 87, 215-251.

GARDINER, J. M., \& JAVA, R. I. (1993). Recognizing and remembering. In A. C. Collins, S. E. Gathercole, M. A. Conway, \& P. E. M. Morris (Eds.), Theories of memory (pp. 163-188). Hove, U.K.: Erlbaum.

GoLD, P. E. (1987). Sweet memories. American Scientist, 75, 151-155.

GRICE, P. (1989). Studies in the way of words. Cambridge, MA: Harvard University Press.

IsEN, A. M. (1985). Asymmetry of happiness and sadness in effects on memory in normal college students: Comments on Hasher, Rose, Zacks and Doren. Journal of Experimental Psychology: General, 114, 388-391.

IzARD, C. E. (1992). Basic emotions, relations among emotions, and emotion-cognition relations. Psychological Review, 99, 561-565.

JANOFF-Bulman, R. (1988). Assumptive worlds and the stress of traumatic events: Applications of the schema construct. Social Cognition, 7, 113-136.

Josephson, B. R., Singer, J. A., \& SAlovey, P. (1996). Mood regulation and memory: Repairing sad moods with happy memories. Cognition \& Emotion, 10, 437-444.

LANG, P. J. (1994). The motivational organization of emotion: Effectreflex connections. In S. H. M. Van Goozen, N. E. Van de Poll, \& J. A. Sergeant (Eds.), Emotions: Essays on emotion theory (pp. 6193). Hillsdale, NJ: Erlbaum.

LaZarus, R. S. (1991). Emotion and adaptation. New York: Oxford University Press.

LeDoux, J. E. (1996). The emotional brain: The mysterious underpinnings of emotional life. New York: Simon \& Schuster.

Levine, L. (2002, April). Cognition and emotion: An overview. Paper presented at the Cognitive Aging Conference, Atlanta.

LoFtus, E. F., \& BuRNS, T. E. (1982). Mental shock can produce retrograde amnesia. Memory \& Cognition, 10, 318-323.

MANDler, G. (1975). Mind and emotion. New York: Wiley.

NiJenhuis, E. R. S., \& VAN DER HART, O. (1999). Forgetting and reexperiencing trauma. In J. Goodwin \& R. Attias (Eds.), Splintered reflections: Images of the body in trauma (pp. 39-65). New York: Basic Books.

NisBetT, R. E., \& Wilson, T. D. (1977). Telling more than we can know: Verbal reports on mental processes. Psychological Review, 84, 231-259.

Öhman, A., Fly Kt, A., \& Esteves, F. (2001). Emotion drives attention: Detecting the snake in the grass. Journal of Experimental Psychology: General, 130, 466-478.

OschNer, K. N. (2000). Are affective events richly recollected or simply familiar? The experience and processes recognizing feelings past. Journal of Experimental Psychology: General, 129, 242-261.

PAnKSEPp, J. (1992). A critical role for "affective neuroscience" in resolving what is basic about basic emotions. Psychological Review, 99, 554-560.

Pillemer, D. B. (1992). Remembering personal circumstances: A functional analysis. In E. Winograd \& U. Neisser (Eds.), Affect and accuracy in recall: Studies of "flashbulb" memories (pp. 236-264). New York: Cambridge University Press.

Reisberg, D., \& Heuer, F. (1992). Remembering the details of emotional events. In E. Winograd \& U. Neisser (Eds.), Affect and accuracy in recall: Studies of "flashbulb" memories (pp. 162-190). New York: Cambridge University Press.

Rubin, D. C. (1995). Memory in oral tradition: The cognitive psychology of epic, ballads, and counting-out rhymes. New York: Oxford University Press.

Safer, M. A., Christianson, S.-Å, Autry, M. W., \& Österlund, K. (1998). Tunnel memory for traumatic events. Applied Cognitive Psychology, 12, 99-117.

TAYLOR, S. E. (1991). Asymmetrical effects of positive and negative events: The mobilization-minimization hypothesis. Psychological Bulletin, 110, 67-85.

Thompson, C. P., Skowronski, J. S., Larsen, S. F., \& Betz, A. L. (1996). Autobiographical memory: Remembering what and remembering when. Hillsdale, NJ: Erlbaum.

Tulving, E. (1985). Memory and consciousness. Canadian Psychology, 26, 1-26.

VAN DER Kolk, B. A., \& Fisler, R. (1995). Dissociation and the fragmentary nature of traumatic memories: Overview and exploratory study. Journal of Traumatic Stress, 8, 505-525.

Wessel, I., \& Merckelbach, H. (1994). Characteristics of traumatic memories in normal subjects. Behavioral \& Cognitive Psychotherapy, 22, 315-324 
APPENDIX

Experiment 1: Correlations $(N=140-143)$

\begin{tabular}{|c|c|c|c|c|c|c|c|c|c|c|c|c|c|c|c|c|}
\hline Characteristic & 1 & 2 & 3 & 4 & 5 & 6 & 7 & 8 & 9 & 10 & 11 & 12 & 13 & 14 & 15 & 16 \\
\hline 1. Details total & & & & & & & & & & & & & & & & \\
\hline 2. Central & -.15 & & & & & & & & & & & & & & & \\
\hline 3. Peripheral & .09 & -.96 & & & & & & & & & & & & & & \\
\hline 4. External & .01 & -.40 & .44 & & & & & & & & & & & & & \\
\hline 5. Internal & -.05 & .43 & -.44 & -.98 & & & & & & & & & & & & \\
\hline 6. Event age & -.06 & -.07 & .08 & .26 & -.25 & & & & & & & & & & & \\
\hline 7. Surprise & .08 & .09 & -.09 & -.07 & .07 & -.04 & & & & & & & & & & \\
\hline 8. Consequences & .07 & -.05 & .06 & -.07 & .06 & .01 & -.11 & & & & & & & & & \\
\hline 9. Intense then & .12 & .18 & -.15 & -.09 & .08 & -.03 & .14 & .24 & & & & & & & & \\
\hline 10. Intense now & .06 & -.08 & .09 & -.05 & .05 & -.09 & .04 & .41 & .31 & & & & & & & \\
\hline 11. Negative then & .04 & .14 & -.11 & .05 & -.04 & .15 & .13 & .19 & .40 & .25 & & & & & & \\
\hline 12. Negative now & .02 & .01 & .02 & -.03 & .06 & .10 & -.04 & .41 & .21 & .50 & .44 & & & & & \\
\hline 13. Vividness & .12 & -.05 & .05 & -.07 & .06 & -.17 & .13 & .14 & .17 & .32 & .05 & .02 & & & & \\
\hline 14. Importance & .11 & .02 & .01 & -.09 & .09 & -.02 & .08 & .30 & .45 & .29 & .42 & .27 & .17 & & & \\
\hline 15. Talked about & .16 & .19 & -.20 & -.01 & .01 & -.16 & .01 & .34 & .22 & .15 & .20 & .13 & .05 & .18 & & \\
\hline 16. Intrusions then & .05 & -.22 & .18 & -.01 & .00 & .01 & -.03 & .37 & .10 & .24 & .29 & .29 & .11 & .31 & .23 & \\
\hline 17. Intrusions now & .06 & -.04 & .03 & -.13 & .13 & -.21 & -.11 & .48 & .26 & .46 & .24 & .34 & .16 & .32 & .26 & .52 \\
\hline
\end{tabular}

(Manuscript received January 13, 2002;

revision accepted for publication June 4, 2002.) 